\title{
Empirical Contributions of International Non-Governmental Organizations (INGOs) to Development: A Reference to World Vision HIV Programmes in Kenya
}

\author{
Jack Ochieng' Nyaliech ${ }^{1 *} \quad$ Magdalene Temko Mangut ${ }^{2} \quad$ Prof. Kenneth Oluoch $^{1}$ \\ 1.Moi University, Department of History,Political Science ad Public Administration, Box 3900-30100,Eldoret \\ Kenya \\ 2.Kenya Medical Training College, Department of Nutrition \& Dietetics, P.O Box 30195-00100 Nairobi, Kenya
}

\begin{abstract}
This study sought to examine the empirical contributions of INGOs on development in regard to health programmes by World Vision Kenya. Studies show that since 1970s INGOs have strongly been recognized as key Third Sector Actors (TSA) on development globally as part of neo- liberal policy. INGOs emerged in Kenya and became part of the development agenda from early 1990s. HIV/AIDS has remained a major setback to development in many countries with Kenya severely affected. There is limited evidence on the empirical contribution of INGOs to development through tackling HIV problems; hence negatively affecting future funding decisions and development operations of INGOs. This study; assessed the role of INGOs in development though economic empowerment and reduction of HIV prevalence rate with reference to World Vision HIV/AIDS programmes in Tinderet Sub-County. The study used Transnationalism Theory (TT) by Robert Keohane and Joseph Nye (1971) to understand the role of INGOs as transnational actors involved in the process of accelerating development through interdependence and cooperation with States to handle global problems. In this study, mixed method was used involving systematic sampling techniques to select 114 beneficiaries of World Vision and purposively selecting key informant respondents. The data collection methods included use of personal interviews, in- depth interviews, and key informant interviews. Both quantitative and qualitative approaches were used for data analysis. The Statistical Package for Social Sciences (SPSS version 20) was used to run descriptive statistics and merged with qualitative data according to the emerging themes using illustrations from the transcripts. The study found that; World Vision empowered HIV infected and affected persons economically and contributed to reduction of HIV prevalence rate in Tinderet Sub- County. The study concluded that INGOs have a role in development by addressing negative effect on health.
\end{abstract}

Keywords: INGOs,Transnationalism, World Vision,MNCs,TNCs.

DOI: $10.7176 / \mathrm{IAGS} / 83-03$

Publication date:June $30^{\text {th }} 2020$

\subsection{Introduction}

In this dispensation of globalization, International Non - Governmental Organization sexist and operate in almost country in the world today. International Non - Governmental Organizations (INGOs) are recognized as key Third Sector Actors (TSA) on the landscapes of development globally. Precise definitions vary as to what constitutes an INGO, and the challenge of analyzing the phenomenon of INGOs remains surprisingly difficult. One reason for this is that INGOs are a diverse group of organizations that defy generalization, ranging from small informal groups to large formal agencies (Lewis, 2007).According to Tandou (2000) INGOs began to emerge in development strongly in the 1970s as part of an alternative model to state-led or macro-level development initiatives influenced by neo-liberal economics and liberal democratic theory which viewed INGOs as the most effective and efficient entities for delivering international relief and development programme (Commins, 2000). Scholars such as Hearns (2002), contends that at the end of the 1970s with the US defeat in Vietnam changed American foreign policy from "military power and coercion alone" but use soft which gave INGOs and civil society in development.

The work undertaken by NGOs is wide-ranging but INGO roles can be usefully analyzed as having three main components: implementer, catalyst, and partner (Lewis, 2007). The implementer role is concerned with the mobilization of resources to provide goods and services to people who need them in fields such as healthcare, microfinance, agricultural extension, emergency relief, and human rights. The catalyst role can be defined as an INGO's ability to inspire, facilitate or contribute to improved thinking and action to promote social transformation through grassroots organizing, group formation, gender and empowerment work, lobbying, advocacy work, and attempts to influence wider policy processes through innovation, and policy entrepreneurship. The role of partner reflects the growing trend for INGOs to work with government, donors and the private sector on joint activities, such as providing specific inputs within a broader multiagency program or project or undertaking socially responsible business initiatives (Lewis,2007).

An assessment of NGOs (both local and international) activities reveals a history of their operations across continents guided by different objectives. In Latin America, the tradition of peasant movements seeking improved 
rights to land, and the efforts of political radicals working towards more open democratic societies both fed into the emergence of local NGOs through the influence of liberal theology by Catholic church (Pearce, 1997).In Asia, a different set of distinctive factors influenced the growth of INGOs, such as the influence of Christian missionaries, the growth of reformist middle class and in India the influential ideas of Mahatma Gandhi, who placed a concept of voluntary action at the center of his vision of change, inspiring organizations such as the Association of Sarva Seva Farms (ASSEFA) seeking to build village level self-reliance through ideas such as credit and savings derived from local self -help traditions, such as rotating credit groups in which household's pool resources into a central fund and then take turns in borrowing and repaying. The rise of the Grameen Bank in Bangladesh has been a home-grown solution to problems of poor people's lack of access to credit, helping to spawn a global micro-finance movement through its distinctive group-based approach to small-scale lending (Lewis,2007). In the countries of Eastern Europe and the former Soviet Union, there were dramatic increases in the numbers of NGOs (both local and international) as Western donors began what they termed democracy promotion and civil society development. (Ishkanian,2006).

Accordingly, INGOs began to proliferate widely in Africa due to the gaps in social welfare left by Structural Adjustment Programs (SAPs). The combination of fewer resources for the state (under SAPs) and foreign aid being channeled through INGOs led to a situation in which INGO development work served as a 'safety net' for African petit bourgeoisie, (Hearn, 2007). The United Nations, World Bank, and IMF have delegated aid programs to INGOs in order to fill the gap that African Governments and private sector was unable to manage (Dibie, 2008). Africa also witnessed proliferation of INGOS due to her inefficient and corrupt governments which could not provide basic social services to the citizens (Edoho,2008).

\subsubsection{Overview of International Non - Governmental Organizations operations in Kenya}

As INGOs emerged in development all over Africa, they inevitably entered Kenya and became part of the development structure to address socio-economic challenges,(Hearn, 2002). In the year 2003, Kenya had registered about 2,511 up from 267 in 1988 a nine-fold increase in the space of just fifteen years as reported by Hearn (2002). Between the periods of 1960 to 2015 a total official development assistant fund grew from US\$21million to US\$ 2.4 billion with a huge amount being channeled through INGOs according to World Bank Report 2015.According to National Council for Non-governmental organization board report of 2008, there was a soaring of NGOs in Kenya both local and International to 3000 in 2004, and well over 4200 by 2007.Numerous international INGO's deliver HIV services, undertake research, engage in policy analysis and advocacy, and play other important roles in Kenya's AIDS response (Muchai, 2014). This recent proliferation of the NGO sector in Kenya carries important implications for the provision of public services to the poor and vulnerable with International NGOs covering a far wider sectoral and geographic base in the country (Kanyinga, 1995).

Among the notable International non-governmental organization in Kenya, are Oxfam International, CARE international, Save the children international, Action Aid International, Islamic relief service among others.

\subsubsection{Statement of the Problem}

Since the 1990s, the role of International Non - Governmental Organizations (INGOs) in development has increased, (Kareithi, 2009). However, the growth of research on INGOs role in development through addressing challenges of HIV/AID is little and this might severely affect future funding decisions due to limited knowledge on their importance (Lewis, 2006). Previous studies on INGOs have focused mostly on arguing whether INGOs are needed or not, or how their role can be best promoted but the actual outcomes of the works of the INGOs in development through tackling HIV/AIDS problems has not been studied thoroughly (Igoe 2005; Tvedt 2006.) .In 2008 , Tinderet Sub-County prevalence rate of $6.2 \%$ and women were likely to be infected at $6.9 \%$ while men at $4.4 \%$ according to Kenya AIDS indicator survey 2012. This has resulted into social-economic burden such as increased number of HIV related orphans, poverty, rights abuses, disease burden and deaths all of which have affected development (KHCP,2016). World Vision which is a renowned INGO globally has been working in Tinderet Sub-County to address social-economic challenges brought about by HIV since the year 2008. This study therefore provided an opportunity to assess the empirical contribution of INGOs in development with reference to World Vision HIV programmes in Tinderet Sub-County.

\subsubsection{Objectives of the Study}

1. To examine the contribution of World Vision on Economic empowerment of HIV affected and infected individuals in Tinderet Sub-County.

2. To assess the contribution of World Vision on HIV Prevalence Control in Tinderet Sub- County.

\subsubsection{Significance of the study}

Discourses about the role of INGOs on development as Third Sector Actors (TSA) within the broader global civil society group is a rapidly growing field. Empirical findings are necessary for academicians, practitioners, 
researches and institutions in decision making. This study will benefit the global body of academician's researchers, policy makers, decision makers, governments, institutions and individuals on the important contribution of INGOS in empowering people living positive with HIV and contribution in prevalence control.

\subsection{Literature Review}

According to a recent report published by World Bank in 2015, Kenya has the second highest number of people living with HIV at 1.6 million people after South Africa with 7 million people in the continent. Based on the recent survey conducted in 2015, the prevalence rate of HIV in Kenya was the 10th highest at 5.9\% with Swaziland being the highest in the world at $28.2 \%$ of persons aged $15-49$ (WHO,2015). In spite of the global efforts to reduce HIV transmission, the prevalence rates continue to increase yearly in Kenya (from5.3\%in2014to5.9\%in 2015)atrend also seen in other countries such as Swaziland (from $27.0 \%$ in 2008 to $28.8 \%$ in 2015) and South Africa (from $18.0 \%$ in 2005 to $19.2 \%$ ) in 2015 .

Despite the high impact interventions, HIV and AIDS have remained as a serious challenge facing human development and achievement of the Kenya Vision 2030 and the sustainable development Goals. Under the Social Pillar of Vision 2030, AIDS is listed as one of the preventable diseases that continue to have a significant impact on the health of the Kenyan population. Because of HIV, human Capital has been lost, diseases burden resulted into poverty and the social structures affected by events such as orphan-hood, school dropouts, child headed families, grandparents overbearing the cost of taking care of the grandchildren, overstretching of health resources at the expense of other diseases and social injustices against women and children (NACC report, 2006). Kenya National HIV Estimates report of 2015 indicated that the number who were living with HIV/ AIDS were approximately 1.6 million people with the bulk being women at 820,000 people, children infected below 15 years were 200,000, while orphans above 1000,000 and annual HIV/AIDS related deaths at 57000 (UNAIDS, 2015) which is coherent with World Bank report of the same year.

According to Coombe, (2002), the financial burden of HIV/AIDS is at least $30 \%$ greater than deaths from other causes because it affects the most productive age group specifically young adults, and because the cost of medication and caring for the sick are staggering and can be prolonged. Further, the burdens of sickness were reported to lead to financial, resource and income impoverishment. While the psychological stress that is a direct consequence of the impact of HIV/AIDs on individual and families can compromise school and work performance, family relationships, and the capacity to take care of children, and may also culminate in risk behavior such as alcohol and drug abuse and in unsafe sexual behavior.

Barnett and Whiteside (2002) pointed out that HIV/AIDS pandemic affects women who already carry a very hard burden in many African Countries from physiological and medical perspective. Notably, Women are solely responsible for the household and the children, and have less financial and material reserves to fall back on. Women also face the risk of abandonment or abuse at the hands of their partners when HIV/AIDS strikes. And when family members fall sick as a result of HIV, its most often the girls who will be removed from schools to take care of those who are sick. This increases their susceptibility to poverty and to the disease because they will probably marry younger and will not have the benefits of an education as pointed by Fylkenes et.at (1997) that low level of educations amongst communities worsens the burden on HIV/AIDS in Africa.

Evidence from various studies have shown the importance of INGOs considering there implementing role in the economic process which is attributed to the fact that they are considered suitable for promoting participatory grassroots development and self-reliance, especially among marginalized segments of society-namely, the poor, women and Children.

According to Vanmeen (2010), some INGOs seek to organize and involve the marginalized groups in their own development while at same time they try to link their clients to the powerful segments of society by providing access to resources that are normally out of reach to the poor. Notably, within development-oriented INGOs offering micro-finance services contribute to the economic improvement of the poor by: bringing in new income from outside the community, preventing income from leaving the community, providing new [self] employment opportunities and stimulating backward and forward linkages to other community enterprises which reliefs socioeconomic pressure.(Vanmeenen,2010).

Literature on INGOS operation reveals their roles in mitigating economic impact of HIV through integral human development programs. INGOS adopted and implemented saving and Internal Lending Communities model to help people infected/affected with HIV and AIDS respond to their vulnerability to economic shocks, cycles and trends through strong social cohesion, self- help and self-reliance in times of hardship beneficial for persons whose immediate survival is at stake (Donahue J.2000).

International Non - Governmental Organizations like Catholic Relief Services have used Saving and internal lending Communities a model with roots in traditional Rotating Savings and Credit Associations (ROSCAs), and Accumulating Savings and Credit Associations (ASCAs). ROSCAs commonly referred to in Kenyan Merry-gorounds, West African Osusus, Mozambican Xitiques and Ethiopian Iqqubs . A SILC group typically comprises of 15-30 self-selecting members, and offers a frequent, convenient and safe opportunity to save. It helps members 
build useful lump sums that become available at a pre- determined time and allows them to access small loans or emergency grants for investment and consumption (Anderson and Baland, 2012). Unlike financial institutions where the interest remains within the institution, SILC members are able to keep and benefit from the interest generated during their savings cycle.Profitsfrominternal fund mobilization are normally shared based on the total amount saved by each individual group member, (Vanmeenen 2010).

Ruth and Muruka, (2007) study of Catholic Relief services operations among the coastal communities infected and affected by HIV in Kenya revealed the important role that INGOs play in helping beneficiaries meet their financial goals in Kilifi, Mombasa and Malindi. The study showed positive effects of CRS programme on financial asset strengthening. As at the end of September 2007, the program in Kilifi, Mombasa and Malindi had reached a total of 3,001 members and facilitated the mobilization of Kshs 1,543,280 (US\$1 21,434) in savings. Review of this study reveals that a total of Kshs 558,915 in loans had been disbursed to 460 borrowers, representing an average loan size of Kshs 1,215 (US\$17.9).

A similar study done by Mwaisaka, (2012) which assessed socio-economic role of Catholic relief service through supporting savings and internal lending communities' project of Bamba division, Kilifi showed how important International Non - Governmental Organizations were in supporting economic activities. This study was able to demonstrate how catholic relief Services assisted in improving household income, initiated income generating activities for some individuals, took care of medical cost, helped purchase of assets like land and also improved the psychosocial wellbeing of HIV infected and affected individuals.

Parker (2000) couldn't agree less than International non-governmental organization offer Microfinance services both credit and savings which help alleviate HIV/AIDS economic stressors through offering households opportunities to build assets, diversify income sources, and generally strengthen their financial footing. Thus, even in its most basic form, access to microfinance services gives households a way to both prepare for and cope with crises. Dipankar \& Njuguna (2008) findings on a study among communities infected and affected with HIV in Homabay County, in Kenya found out that the micro-finance services in additional to psychosocial support like counseling was a going along way to support these communities meet pressing socio-economic needs.

In Kiambu County,Kenya,Kerubo (2000) noted that Child Fund International was offering an efficient Microfinance services to HIV/AIDs infected and affected through 'Weaving the Safety Net' and many benefited from social capital that could sustain them and improve their standard of living as result of Increased access to financial services, increased household incomes, Improved self-esteem, Increased household assets like land, dairy cows among others and improved financial literacy amidst the health challenges.

Studies by Joanna and Morton, (2005) on Kitovu Mobile Farm Schools Project funded by Medical Missionaries of Mary in Zimbabwe and Mweene (2006) on World Vision interventions in Gwembe Valley in Zambia concluded that INGOs were offering agricultural inputs (fertilizes, machines and loans) education on crop production practices, livestock restocking where household received heifers, bull's goats for purposes of improving the local breeds, vocational trainings on bakery, hair dressing, tailoring, masonry, carpentry among others which improved to the living standard of the vulnerable communities.

There is no doubt that high HIV prevalence rates slows development of a community and a country because HIV/AIDS affect five general areas of the economy namely; individual households, private sectors, agriculture, health, and education. The impact on the household is potentially the largest. Studies have shown that HIV particularly in African affect people in their prime ages which results into reduced per Capita income due to slowed labor productivity (UNAIDS,2016).

A number of studies have shown that international non - Governmental Organizations continue to participate in efforts to reduce prevalence rate of HIV among communities. Theuri, (2014) in her study on the contribution of three International Non - Governmental Organizations namely; Family Heath International (FHI), Elizabeth Glaser Pediatric AIDS Foundation (EGPAF) and Programmes for Appropriate Technology in Health (PATH) to reducing prevalence rate acknowledged that indeed they were doing much. The INGOs were offering the male circumcision services whose goal was to help reduce incidence of HIV infections in order to achieve an AIDS-free generation among non-circumcising communities, providing HIV literacy and testing services to targeted adolescents in schools, uniformed non-military force, funding local organization to promote HIV prevention services like offering Anti-retroviral therapy reduced prevalence of HIV greatly.

A review of International Planned Parenthood federation activities (an international non- governmental organization) operations in Nigeria revealed the various HIV prevention activities they have been implemented with the aim to alter HIV spread. These included educating long distance drivers on safe sex, use of religious leaders who have been trained on HIV prevention to encourage their flocks to implement prevention strategies, promoting prevention of HIV in the communities through formation of community support groups, provision of material needs,spiritual support and rehabilitating those suffering from the AIDS disease. International Planned Parenthood federation also worked with churches, used informal education, involved people living with AIDS thereby reducing stigmatize and encouraging voluntary testing. Planned Parenthood Federation Nigeria trained members of OKADA (motorcycle transportation) union on HIV/AIDS with the need to reduce the prevalence 
amongst them (IPPF annual report2014).

Arguably, Margaret et al., (2008) in their study of MSF(Me'decins Sans Fronti'eres) a non- government international organization headquartered in Paris and AMRE in Kibira slums,Kenya revealed that international Non - Governmental Organizations played a great role in finding HIV prevalence in partnership with the civil society groups, Ministry of health and the community members. This study noted that these INGOS supported carrying out awareness, provision of treatment, condoms, HIV testing and counseling, Educating HIV positive people on the need to avoid infecting others, offering psychosocial support, and trainings among other activities which have reduced stigma and discrimination assisted thereby altering Prevalence rate of HIV among slum dwellers.

WHO (2013) study which analyzed the impact of PLHIV support groups in 7 Sub-Saharan countries acknowledge that INGOs were instrumental in prevalence control through supporting community lead HIV prevention initiatives aimed at encouraging pregnant mothers seek ANC services, encouraging general population to go for HIV testing, referral of HIV positive patients to clinics and fighting stigma and discrimination.

\subsubsection{Transnationalism Theory}

Robert Keohane and Joseph Nye(1971) in explaining Transnationalism Theory (TT) noted that the "state-centric" view of world politics was inadequate particularly after the end of World War II contrary to the realist view. Transnationalism theory had its root in liberal pluralism as pointed out by Stephen Krasner (1982) building on the work of Keohane and Nye that with globalization, the boundaries of states collapsed as a result of; unhindered movements of information, money, physical objects, people, or other tangible or intangible items across state boundaries. In the groundbreaking work on interdependent Transnationalism (Keohane and Nye, 1971), allentities interacting across national boundaries with at least one non-state agent present were considered transnational. According to this theory, the Transnational Actors (TA) are; Intergovernmental Organizations (IGO), Transnational Cooperation's (TNC)/Multinational Cooperation's (MNC) and International Non - Governmental Organizations (INGOs) which accelerate the process of development through interdependence and cooperation (Keohane and Robert 1971). Clearly, all of these actors have become significant interlocutors for the management of global issues. Accordingly, transnational actors are objective and issue focused with minimal control from states which lent this theory relevance in understanding the role of INGOs understudy.

\subsection{Methodology}

This was a descriptive concurrent mixed method study which employed both quantitative and qualitative approaches in collecting and analyzing data with the main purpose being triangulation. The study was conducted in Tinderet Sub-County in Nandi County, Kenya where World Vision had been implementing a HIV/AIDS program since 2009. The study primarily targeted individuals from households of HIV/AIDS infected and affected persons who had been beneficiaries of World Vision for a period of 5 years to be able to measure the real outcomes. From the total 381eligible households, 114 were sampled using systematic random sampling technique (Mugenda and Mugenda, 2003). Purposive sampling was used to select 24 participants from World vision staffs, health care workers, Government administrators, non-beneficiaries and community opinion leaders for as Key informants. Data was collected from primary respondents using semi structured questionnaires, while in-depth interview was used to obtain information from the key informants. Photographs of the various projects that World Vision undertook were taken. The Statistical Package for Social Sciences (SPSS version 20) was used to run descriptive statistics such as frequency and percentages so as to present the quantitative data in form of tables and graphs based on the major research questions. The qualitative data generated from open ended questions will be categorized in themes in accordance with research objectives and reported in narrative form along with quantitative presentation through merging process. The qualitative data were used to triangulate the quantitative data.

\subsection{Results}

The tables herein show that majority of the primary respondents were women at $56 \%$ while males were at $44 \%$. This implies that women carry the burden of HIV than Men in communities and therefore need to be prioritized in HIV/ AIDS programme interventions. Majority of the respondents were between 30-45 years at 48\%, $45-60$ years followed at $26 \%$, among $18-30$ years were $15 \%$ and finally above 60 were at $11 \%$.From this results is goes without saying that the burden of HIV and prevalence was higher among women below 45 years.

Figure 1 Shows that majority of respondents were married persons at $72 \%(82)$, followed by widowed $15 \%$ (17), single $7 \%$ (8) and separated 6\% (7) category the least. HIV prevalence was high among married partners leading to high incidences of orphan hood and widows' hence high socio-economic burden.

As presented in the tables, evidence reveals that 53\% (60) had only primary education considered the lowest level of education a person can attain in Kenya, while 17\% (20) of the respondents had only Secondary or O level education which is the second lowest level of education, Tertiary Educationwasreported at 11\% (12), those with University education at 4\% (5) and finally those who have never attended school were at $15 \%$ (17) of the 
respondents all of whom were HIV infected. This clearly points to the fact that HIV affect communities with low levels of education.

Table 2 Showing Gender of the respondents.

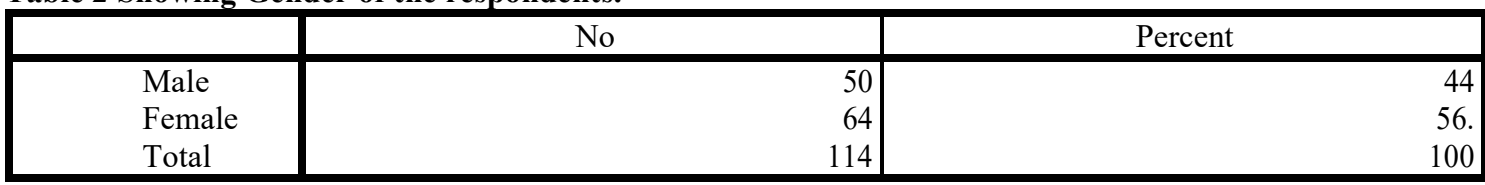

Source: Field Data 2016

Table 3 Showing Age of the respondents

\begin{tabular}{|c|l|l|}
\hline Category of years & Frequency & Percent \\
\hline $18-30$ years & 17 & 15 \\
30-45years & 55 & 48 \\
45 -60 years & 30 & 26 \\
Above 60 years & 12 & 11 \\
Total & 114 & 100 \\
\hline
\end{tabular}

Source: Field Data 2016

Figure 1: Showing Marital Status

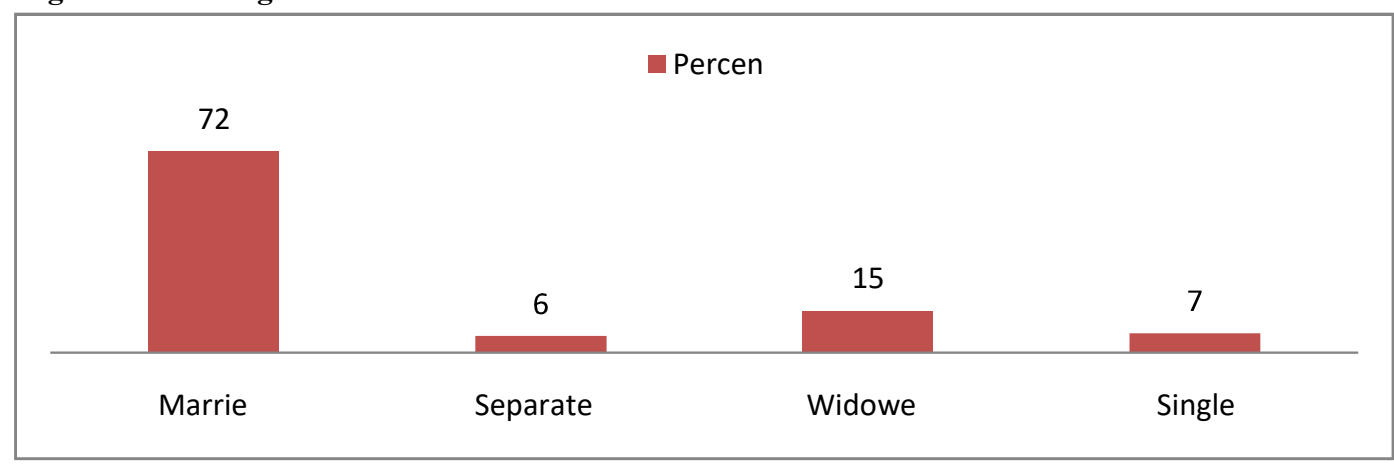

Source: Field Data 2016

Table 4:Education Level

\begin{tabular}{lrr}
\hline & Frequency & Percent \\
\hline No education & 17 & 15 \\
Primary & 60 & 53 \\
Secondary & 20 & 17 \\
Tertiary & 12 & 11 \\
University & 5 & 4 \\
Total & 114 & 100.0 \\
\hline
\end{tabular}

Source: Field Data, 2016

\subsubsection{Economic empowerment}

From the findings, $35 \%$ of the primary respondents reported income generating activities, $30 \%$ indicated capacity building trainings on agri-business, $21 \%$ reported initiation and running of saving andinternal lending communities (SILC), 7\% showed they marketed agricultural proceeds from the beneficiaries and $6 \%$ noted that they sponsored them to visits other agri-business centers for educational, skills and knowledge building. During the study the following projects were visited;

i. Gotnelel and Koilenge Community based organization Cattle dip and water project with 357 households' beneficiaries and serving about 1500 household customers. Through the support from World Vision, they managed to purchase hydram water pump, constructed two water tanks with a capacity of 100000 litres, water kiosks and pipes at cost of $\$ 13,000$ for the water project with some funding going to renovation of cattle dip which was given at a tune of $\$ 2000$, the monthly amount raised from these two projects were about approximately $\$ 600$ and $\$ 1300$ respectively and members could borrow the money for personal or business use at a fixed interest rate.

ii. Kaptinge Self Help Group and Kapsong Community based organizations with 100 households as 
beneficiaries received support of about $\$ 3500$ to run a bakery shop or confectionary with some of the items produced for sale being bread, cakes, biscuits and among others and sold to the nearby markets, homes, Multinational teas estates and schools with monthly income averaging about $\$ 560$ and $\$ 730$ respectively and the proceeds were pooled together from which members could borrow and repay with some interest.

iii. Kiptebes Community based organization received financial support from World Vision to start Fish, Bee and horticultural farming. The group received a seed capital of about $\$ 7500$ which they used to construct 4 fish ponds, buy fingerlings, construct 40 beehives and put up a green house. The monthly income from these three projects enabled the group raise about $\$ 540$ of which members were allowed to borrow from and repay at 5\% interest rate. This group was serving 75 households as the intended beneficiaries.

iv. Kabungut Women Group with 60 household beneficiaries received donations of 3 cockerels and 17 hens/layers and a seed capital of \$1000 money for table banking from World Vision. World vision provided feeds and vaccinations for a period of one year after which members started selling eggs and chicken to the local market. Each member was able to raise \$ 50 a month from the sale of the eggs only. Equally World Vision trained them to run the poultry farming alone without any support for sustainability purposes. The group could also borrow within the framework of table banking and pay within a period of 3 months at 5\% interest. A study participant explained to the study that through these income generating activities, some members were able to start their own side businesses like running small kiosks, groceries, saloons, selling second hand clothes among others which they never used to do.

v. Finally for Kapsoen -Kibingei Community development group, World Vision provided seed money that enable them to put up three green houses at a cost of $\$ 3500$ and helped them rent 5 acres where they planted about 1000 coffee seedlings to be managed for 10 years. Through the proceeds from the greenhouse which was raising about $\$ 350$ a month, the group members managed to purchase 3 motorbikes which were offering commercial transport for goods and People within the locality at a cost from which they could comfortably raise about $\$ 600$ per month. The profit formed part of the capital for table banking where members could borrow and repay for duration of up to 6 months at $10 \%$ interest rate. Beneficiaries were 50 households.

Furthermore, WV assisted the beneficiaries opening their eyes to various government and non-government agencies who would also partner with them in supporting various ideas and income generating activities. Notably, UWEZO FUND, WOMEN ENTEPRISE FUNDS, funds from ministry of agriculture which are basically government initiates reached these groups because of World Vision to supplements the efforts and for sustainability. World Vision embraced ownership of the economic activities through empowering households and communities not individuals for sustainability purposes as one study pointed out that; "The policy of World Vision is to lead community driven projects therefore beneficiaries are involved in their activities to have a higher chance of success and sustainability”. (Source: Interview with Key informant).

During the site visits, the researcher saw bakery machines, poultry houses, beehives, green houses, fishponds, cattle dips and water Kiosks for beneficiaries supported by World Vision. Notably, in beneficiaries' farms, there were crops like bananas, vegetables, cereals and dairy goats' courtesy of World Vision support. Furthermore, beneficiaries provided the researcher with registers which had all the names of saving and internal lending community members and safe boxes which they were using to keep the money. These were strong suggestions of what economic role World Vision was playing in the lives of these infected and affected persons.

\subsubsection{HIV prevalence Control contributions}

From the interview with the study participants on the contribution to prevalence control, $25 \%$ reported distribution of Condoms, $32 \%$ they companied against stigma and discrimination, $15 \%$ reported encouraging of PLHIV to join psychosocial support groups, $10 \%$ reported that supporting pregnant women to attend ante-natal clinic and also give birth in health centers where they could get HIV prevention services.Futhermore, $7 \%$ reported that World Vision worked with community members to support various HIV preventive initiatives, $8 \%$ indicated referral of people who test HIV positive to comprehensive care centers and finally 3\% showed they help build health centers where people could go and be tested. World vision supplied HIV test kits, renovated some Voluntary testing centers, and trained health care workers on HIV testing, providing information, education and communication material on HIV prevention for literacy purposes and supported the hospitals to conduct HIV testing outreaches .The impact of these activities were; reduced HIV related stigma, majority of community members had correct information on HIV which devoid of myths, many pregnant women went for ante-natal care services and a high number delivered in the hospitals where they got HIV preventive services, the number of people who accessed HIV test increased, condom consumption went up and many people who tested HIV positive were enrolled into comprehensive clinics. 


\subsection{Discussion}

HIV/AIDS affect five general areas of the economy and the impact on the household is potentially the largest. Studies have shown that HIV particularly in African affect people in their prime ages which results into reduced per Capita income due to slowed labor productivity (UNAIDS,2016).KASF (2014) indicated that HIV burden and prevalence was higher among those below 45 years who are relatively younger people and society depends on for social- economic development.Furthermore, the negative effects are made with low education levels more than those higher literacy levels as reported by Fylkesnes et.al (1997) which could explain why the high HIV burden in Tinderet more than other sub-counties(Districts) in NandiCounty. Coombe (2002) pointed out that the financial burden of HIV/AIDS is at least 30\% greater than other illnesses because it affects people in their most productive years which mirrors the findings of this study that most affected were between 30-45 years. Barnett and Whiteside (2002) argued that HIV /AIDS lead to financial, resource and income impoverishment and put strain on individuals and households which in turn results into psychological stress. Dicklich (1998) pointed out that the role of INGOs on economic development and empowering communities towards development was a reality because of targeting and being responsive to marginalized groups in society like people infected and affected with HIV which if left for States alone particularly in Sub-Saharan Africa, the damage will be great.

Parker, (2000) noted that International non-governmental organization help alleviate HIV/AIDS economic stressors through; offering households opportunities to build assets, diversify income sources, and generally strengthen their financial footing. Notably, White et.al (2005) argued that INGOs are able to help HIV infected and affected improve their living standards though economic empowerment which are well thought of and in line with the needs of the beneficiaries. In -deed the findings of this study revealed that World Vision contributed immensely to economic empowerment of HIV/AIDs infected and affected beneficiaries. Majority of participants agreed that there were improved living standards and beneficiaries were able to buy cloths, household items like seats, Radios, Television, solar panels for lighting and were able to eat three course meals on a daily basis and treating themselves when they are sick as an evidence of economic empowerment. One study participants noted that;

"My living standard improved because of the support from World Vision International which enabled me to construct an iron sheet roofed house from a grass thatched for me and my 3 children".

According to Ozcan (2005), When HIV strikes a poor family, or where the bread winner no longer provides, its economic effect normally results into sale of household assets to address the disease challenges and without early intervention, situation normally results into absolute poverty. World Vision Economic intervention enabled the beneficiaries acquire assets such as land, increasing crop acreage, purchasing sofa sets, Wall units, opening small kiosks/businesses like saloons, groceries, purchase of cows, goats, sheep's, chicken, donkeys for transportation services, planting cash crop like sugarcane, Tea and Coffee. Kerubo etal, (2009) in s similar study noted that international nongovernmental organization economic interventions to HIV/AIDS infected and affected have the capacity to support increased household assets like land, dairy cows among others and improved financial literacy. Participants in this study indicated that the economic initiatives cushioned them from selling household assets as they had alternative means of surviving. A study participant had this to say;

"Ever since World Vision started offering support I have seen a reduction in the number of agreements that I write for sale of assets from the beneficiaries to meet medical and other family needs like school fees".

Villarreal (2002) pointed out that INGOS are critical in empowering AIDS burden communities with agricultural and business knowledge very necessary to prime the pump for their economic freedom. Further, Mwaisaka, (2012) pointed out that INGOs were instrumental in ensuring that household savings are achieved among HIV infected and affected communities. Evidence from thisstudy suggested that World Vision economic empowerment helped the beneficiaries be self-reliant, furthermore the majority also reported improved agribusiness knowledge and skills some of which enabled them to partner with other financial institutions like government line ministries, government lead Micro-finance services like Youth Enterprise Fund, Women Enterprise Funds, Uwezo Fund among others which increased their financial base and saving patterns. This is in line with Dipankar \& Njuguna (2008) findings on a study among communities infected and affected with HIV in Homabay County, which found out that the micro-finance services in additional to psychosocial support like counseling was a going along way to support these communities meet pressing socio-economic needs Literature on INGOS operation reveals their roles in mitigating economic impact of HIV through integral human development programs. In another study by Donahue (2000), it was noted that INGOS adopted and implemented saving and Internal Lending Communities model to help people infected/affected with HIV and AIDS respond to their vulnerability to economic shocks, cycles and trends through strong social cohesion, self- help and selfreliance in times of hardship beneficial for persons whose immediate survival is at stake.

From the foregoing, WV impacted positively on the lives of the beneficiaries through various economic empowerment initiatives which contributed to development in Tinderet and complemented the activities of the State a fact that UNDP (2017) acknowledged by referring to the partnership between states and non-state actors 
like INGOs as having the capacity to help states meet immediate economic needs of their citizens in a more coordinated way. It is from this perspective that Transnationalism theory of Keohane and Nye (1971) becomes relevant in explaining this study by pointing out the role of INGOs and their capacity to "prime the pump "for economic development when they cooperate with states on specific issue areas like HIV/AIDs as in-deed shown by World Vision.

\subsubsection{Contribution of World Vision in reducing prevalence rate of HIV in Tinderet}

There is no doubt that high HIV prevalence rates slows development of a community and a country (UNAID, 2016)and the general understanding is that if HIV infection rates are controlled it will positively impact on the fight against the disease because lesser people will require the costly services and their lives will be more productive thereby contributing to development (UNAID 2015). These finding were analyzed based on the three HIV prevention strategies namely biomedical, behavioral and structural interventions supported by World Vision in Tinderet and also recommended by WHO. In line with HIV prevention models the study found out that World Vision Contributed to reduction of prevalence rate through the following ways;

Tinderet Constituency AIDS control Coordinator reported that in the year 2015 alone a total of 187000 condoms had been distributed to Tinderet by World Vision (KDHS, 2015)from 80,000 in 2012. More clearly, from 2012-2015, the Constituency AIDs Control Council coordinator reported that the demand for condom use grew steadily which required them to increase condoms dispensers from 85 to 217 due to high demand. World Vision officer in charge of Health and HIV program informed the study that that the yearly usage of condom had increased from $31 \%$ in 2012 to $70 \%$ in 2015 .

Accordingly the Sub-County AIDs/STI Coordinator noted behavioral interventions like anti-stigma and discrimination against PLHIV in each Sub-location such us continuous HIV education and awareness campaigns delivered during Baraza (Village meetings), road shows and community dialogue days and others such as using Community Based Organization, churches and institutions like schools to conduct anti-stigma and discrimination campaigns encouraged people to come out to be tested and also embrace those who tested HIV positive. Data from Tinderet Demographic health survey recorded that in 2012 about 11471 to 24226 in 2015 a clear indication of the contribution of World Vision. A review of International Planned Parenthood federation HIV prevalence control activities of 2014 in Nigeria suggested similar outcomes such as reduced stigmatize and increased voluntary testing. Further, Theuri (2014) found out that Family health International supported such behavioral interventions like stigma and discrimination campaigns and they influenced people's attitude towards those with HIV. Evidence from studies in Zambia and Kenya in 2012 revealed that with reduced stigma and discrimination across all levels, PLHIV will be willing to disclose their HIV status while those who have never tested will not fear but go for test thereby promoting HIV prevention (WHO,2013) which supports these outcomes.

Analysis of the findings revealed that World Vision encouraged formation of PLHIV support groups that supported referral of people for HIV testing, fighting for the rights of the infected/affected as a watchdog unit, encouraged people to adhere to Anti-retroviral drugs, promoted use of Condoms, offered psychological support to reduce stress or depression, assisted in tracing defaulters from HIV medication to return to treatment and run away from stigma which affect PLHIV and help in fighting stigma and discrimination by openly and significantly disclosing their HIV status and discarding myths around it. These findings are in line with 7 studies in South African found out that Support groups were key in achieving PLHIV treatment literacy, adherence, and above all it enables PLHIV to disclose their status with potential prevention benefits. The studies further found out that Support group assist PLHIV to avoid risky sexual behaviors (having unprotected sex) and habits like drugs and substance abusers which also increases prevention benefit (WHO,2013).

According to WHO study published in 2013, Anti-retroviral drugs are a tool for treatment and prevention. The study noted that HIV positive Women who are pregnant can deliver infants and raise them well without infecting with HIV if both uses ARVs particularly the mother. Furthermore, when people get to know their HIV status, they can make an early decision to use ARVs to attain quality health, reduce chances on infecting others because of suppressed viral load and also decide to avoid infecting others, accordingly if people go for HIV testing they can choose to remain negative or use ARVs and all are Bio-medical preventive interventions (WHO, 2013).Sub-County Public Health Nurse acknowledged that most pregnant women were going to ante-natal which increased the chances of them also going to deliver in the hospitals. Information from Tinderet Sub-County Medical department and from the interviewed participants, it is acknowledged that the number of Pregnant women who went for ANC services increased from 750 in 2012 to 2095 in 2015, while those pregnant mothers who whose babies were started on prophylaxis moved from 28 to 63, numbers of those general population on ART moved from 161 to 307 while those who where started on pre-exposure prophylaxis moved from 28 to 63 during the same period. Noticeably, World Vision assisted greatly in ensuring that pregnant women gave birth in health facilities where they could be tested before and after delivery which greatly contributed to prevalence control.

These findings cannot agree less with Margaret et al., (2008) in their study of MSF(Me'decins Sans Fronti eres) in Kibira slums, that revealed international Non - Governmental Organizations played a great role in 
HIV prevalence control by supported carrying out awareness, provision of treatment, condoms, HIV testing and counseling, Educating HIV positive people on the need to avoid infecting others, offering psychosocial support, and trainings among other activities which have reduced stigma and discrimination assisted thereby altering Prevalence rate of HIV among slum dwellers.

All these preventive efforts by World Vision since 2009 in Tinderet Sub-County contributed to reduction in the overall prevalence rate based on data from $6.2 \%$ (women were likely to be infected at $6.9 \%$ while men at $4.4 \%$ ) in 2008 to $3.6 \%$ (women being the most vulnerable at $4.9 \%$ and men at 3.6\%) in 2012 (KAIS,2012) therefore suggesting an important role played by INGOs in accelerating development through HIV prevalence control and cementing the position of Transnationalism theory in encouraging partnership as outlined by UNAID (2017) its HIV prevention road map 2020 and achieve sustainable development goal 3.

\subsection{Conclusion and Recommendations}

Based on the findings from the data collected and analyzed; First,it's evident that World Vision contributed in development through economic empowerment and reduction of HIV prevalence rate in Tinderet Sub-county. Secondly, Transnationalism Theory (TT) has been applied to help understand the important role that INGO play in development by tacking HIV problems besides the state. Thirdly, it was also found that though World vision in Tinderet interventions took the largest percentage, there were other organizations also providing support to people infected and affected with HIV whose contribution were equally important. Key among them was Community Based Organizations and Government Line Ministries.Lastly, the study concluded that INGOs have a role in development through tackling socio-economic problems and fight prevalence rate of HIV incommunity.

The study recommended that; Government micro-finance institutions should transform socio- economic lives of people living with HIV and improve linkage and awareness to bridge gap of the many who have been missing out. Further, relevant government ministries working with International Non - Governmental Organizations should properly document implementation of activities and their impacts. Most importantly again, Programmes intended to benefit beneficiaries should be carefully thought of and their participation in selection should be considered to enhance ownership. Finally, more theoretical explanations such as Transnationalism Theory (TT) by Robert Keohane and Joseph Nye assist practitioners to explain the role of INGOs in tackling transnational problems likeHIV for meaningfuldevelopment.

\section{References}

Anderson, S. \& Baland, J. (2002).The economics of ROSCAs and intra household resource allocation. 117(3) 963995. Oxford University Press.

Kusiima,A.(2009). The Impact of HIV and AIDS care and support interventions on households welfare in Uganda:A A case study of Kyamukaama and Buwunga Sub-Counties,Masaka District.Unpublished masters thesis,Makerere University,Uganda.Retrived from http://hdi.handle.net/10570/2388

Brass, J.N. (2012). Blurring Boundaries: of NGOs into Governance in Kenya. Governance, vol. 25, no. 2 , pp. 209 235.Blackwell Publishing Inc

Castells, M. (2008). The New Public Sphere: Global Civil Society, Communication Networks, and Global Governance", Annals of the American Academy of Political and Social Science, vol. 616, no. 1, pp. 78-93.

Mweene, C. (2006). An Assessment of Community Participation and Empowerment through Non - Governmental Organizations' development work among the rural poor. The case of World Vision's intervention in the Gwembe Valley, Zambia.Master's thesis Norwegian University of Science and Technology.Retrived from https://core.ac.uk/download/pdf/52108448.pdf

Dipankar, D. \&Njuguna, J. (2008). Microcredit for people affected by HIV and AIDS: Insights from Kenya, SAHARA-J: Journal of Social Aspects of HIV/AIDS, 5:2, 94- 102, DOI: 10.1080/17290376.2008.9724906.

Donahue J. (2000). Microfinance and HIV/AIDS: ... It's Time to Talk. Retrived from http://womenchildrenhiv. org.za/pdf/p09-of/of-07-02.pdf.

Edoho, (2008).Strategic repositioning of NGOs for Sustainable development in Africa.In Non-Governmental Organizations and sustainable development in Africa, edited by RobertA.Dibie 223.

Lanham,MD:Lexington BooksNewYork cold war world. J Int Dev.;7(6):849856.http://dx.doi.org/10.1002/jid.3380070604

Hearn, J. (2002). The US democratic experiment in Ghana. In T. Zack-Williams, D. Frost, \& A. Thomson (Eds.), Africa in crisis : new challenges and possibilities (pp. 97-108). Pluto Press.

Hearn, J. (2007). 'African NGOs: The New Compradors?', Development and Change, 38 (6): 1095-1110 http://www.m2mafrica.org/ [20 $0^{\text {th }}$ December 2017].

Igoe, J. (2005), 'Preface'. In Igoe, J. and Kelsall, T. (eds.), Between a Rock and a Hard Place - African NGOs, donors and the state, Durham: Carolina Academic Press.

Ishkanian, A. (2006). From inclusion to exclusion: Armenian NGOs'participation in the PRSP.Journal of International Development, Vol. 18(5), 729-740. 
JAAIDS (2000) . Nigerian churches agree to fight HIV/AIDS. Nigeria AIDS Bulletin; Retrived from www.nigeriaaids.org.

White, J. \&Morton, J. (2005). Mitigating Impacts of HIV/AIDS on Rural Livelihoods: NGO Experiences in SubSaharan Africa. Development in Practice Vol. 15, No. 2 (Apr., 2005), pp. 186-199.

Kanyinga, K. (1995).'The Changing Development Space in Kenya: Socio-Political Change and Voluntary Development Activity', in Gibbons, P., ed. Civil Society and Democracy.

Kareithi, R., et al., ( 2009). Location of development NGOs providing HIV and AIDS services to young people in Cape Town, South Africa. J Soc Dev Afr;24(2):9 36.

Kenya National AIDS Control Council (2006). Assessment of the socio-economic Impact of HIV/AIDS on key sectors in Kenya. Government of Kenya

Kenya National AIDS Control Council (2014). 'Kenya AIDS Strategic Framework 2014/2015 2018/2019'.Government of Kenya

Kenya National AIDS Control Council (2014). 'Kenya AIDS Strategic Framework 2014/2015 2018/2019. Government of Kenya.

Kenya National AIDS Control Council (2014).Kenya AIDS response progress report Progresstowards zero. Government of Kenya.

Kenya National Bureau of Statistics and Society for International Development ((2013).Exploring Kenya's Inequality:Pulling apart or pulling together? A bridged report.Goverment of Kenya.

Kenya National Bureau of Statistics (2015). 'Kenya Demographic and Health Survey2014.Government of Kenya.

Keohane, R., \& Nye, J., (Eds.). (1971). Transnational relations and world politics. Cambridge, MA: Harvard University Press.

Lewis, D. (2006). Issues and priorities in non-governmental organisation research. $11^{\text {th }}$ edition ((London:Routledge ,2006).

Lewis, D. (2007). The management of non-governmental development organization,2nd edition(London:Routledge ,2007,pp.290).

Kerubo,R. McCormick,L. \& Kinoti ,D. (2009). "Weaving the Safety Net” Program, Kenya: Improving Access to Formal Microfinance Institutions for HIV- \& AIDS- Affected Vulnerable Households Printed in the United States of America . Retrived fromwww.seepnetwork.org.

Mwaisaka, J. (2012). The effects of savings and internal lending communities' Project on the sustainability of the socio-economic status of The intended beneficiaries of Bamba division, Kilifi County.Retrived from https://mangotree.org/files/galleries/741

National Aids Control Council, (2014). Kenya aids Strategic framework 2014/2015 - 2018/2019.Government of Kenya.

Kanyinga, K.\& Ng'ethe, N. (2013).The politics of development space: the state and NGOs inthe delivery of basic services in Kenya", University of Nairobi. International Planned Parenthood Federation(2014) .Annual performance report.Nigeria

Odindo, M. A.,\& Mwanthi (2008). "Role of Governmental and Non - Governmental Organizations in Mitigation of Stigma and Discrimination Among HIV/AIDS Persons in Kibera, Kenya." East Africa Journal of Public Health 5(1): 1-5.

Parker, J. (2000). Discussion paper: Microfinance and HIV/AIDS. Development Alternatives, Inc. (DAI), USAID Microenterprise Best Practices (MBP) Project.

Pearce, J. (1997). Between co-option and irrelevance? Latin American NGOs in the 1990s. In D. Hulme \& M. Edwards (Eds.), Too close for comfort? NGOs, states and donors.

Tandon, R. (2000) Riding high or nosediving: Development NGOs in the new millennium, Development in Practice, 10:3-4, 319-329, DOI: 10.1080/09614520050116488

Muchai, R. N. (2014) Factors Influencing The Sustainability Of HIV/AIDs Control Strategies By Non Governmental Organizations In Kenya:A Case of Kibera slums, Laini Saba Ward In Nairobi County. Unpublished master's thesis University of Nairobi.Retrived through http://erepository.uonbi.ac.ke

Muruka,G,.\& Odera, R. (2007) Catholic Relief Services (CRS) and Savings andInternal Lending Communities (SILC) Programme in Kilifi and Malindi.A review report retrived from https:/www.microsave.net

Commins, S. (2000). "NGOs: Ladles in the Global Soup Kitchen?” in ed. Jenny Pearce, Development, NGOs and Civil Society: Selected Essays from Development in Practice, (Oxford: Oxfam GB, 70, 71)

Tvedt, T. (2006), 'The International Aid System and the Non - Governmental Organizations: a New Research Agenda', Journal of International Development, 18,677-690.

UNAIDS (2012) . 30th Meeting of the UNAIDS Programme Coordinating Board.Retrived from http://www.unaids.org

UNAIDS (2007)' PracticalGuidelines for Intensifying HIV Prevention".Retrived from http://www.unaids.org

UNAIDS (2010) 'Combination HIV Prevention: Tailoring and Coordinating Biomedical, Behavioral and Structural Strategies to Reduce New HIV Infections'.Retrived from http://www.unaids.org 
UNAIDS (2012). Getting to Zero: 201-IOIS Strategy Development. Geneva: Retrived from http://www.unaids.org

UNAIDS (2016)'HIV and AIDS estimates.Retrived fromhttp://www.unaids.org.

UNAIDS (2017)'Ending AIDS: Progress towards the 90-90-90 target.Retrived from http://www.unaids.org

UNAIDS (2002) AIDS epidemic update. Geneva. Retrived from http://www.unaids.org

UNDP, United Nations Development Programme (2010), The Real Wealth of Nations: Pathways to Human Development. Human Development Report 2010. 20th Anniversary Edition. Available at http://hdr.undp.org/en/reports/global/hdr2010/chapters/en/. Accessed 31.3.2011.

United Nations Development Programme (2017) HIV, Health and Development Annual Report 2016- 17.Retrived from https://www.undp.org

Vanmeenen, G. (2010).Voices from Africa; The benefits of integrating SILC into development programming. CRS report Kenya. Retrieved from https://mangotree.org/files/galleries/729_SILC_Voices_from_Africa.pdf

Villareal, M. (2002) 'Perspective: How can agriculture face the challenges posed by HIV/AIDS?', New Agriculturalist online, available at www.new-agri.co.uk/02- 5/perspect.html

WHO. (2013) Consolidated Guidelines on the Use of Antiretroviral Drugs forTreating and Preventing HIV Infection: Recommendations for a Public Health Approach.

World Bank Cost of inaction report (1999). Intensifying action against HIV/AIDS in Africa: responding to a development crisis. (Washington: World Bank)Google Scholar

Theuri,N. (2014) Indicators of NGOs Success \& Impacts on NGOs Role in HIV Policy Process in Kenya.Published Master's thesis University of Malmo. Retrived from https://pdfs.semanticscholar.org/ b757/2fae2ef794f2edb00c1243a8ba54e2f91b08

Coombe, Carol (2002), Mitigating the Impact of HIV/AIDS on Education Supply, Demand and Quality. In AG Cornia (ed.), AIDS, Public Policy and Child Well-being. UNICEF: Innocenti Research Centre, Florence. To be published 2007 as a hard-cover Unicef book, by Innocenti

Barnett, T, \&Whiteside, A. (2002).AIDS in the Twenty-First Century: Disease and Globalization.Palgrave publishers 2006.

Ozcan, K, . et al (2005), “Asymmetric Shocks and Risk Sharing in a Monetary Union: Updated Evidence and Policy Implications for Europe," In Harry Huizinga and Lars Jonung, eds. The Internationalisation of Asset Ownership in Europe, Cambridge University Press, New York.

Fylkesnes, K., et al. (1997). The HIV epidemic in Zambia: socio-demographic prevalence patterns and indications of trends among childbearing women.Publication AIDS(London Engalnd).Vol.11,pgs 339-49. 